\title{
Sex and Heart Failure Treatment Prescription and Adherence
}

\author{
Marta Farrero ${ }^{1}$, Lavanya Bellumkonda ${ }^{2}$, Inés Gómez Otero ${ }^{3,4,5}$ and Beatriz Díaz Molina ${ }^{6,7 *}$ \\ ${ }^{1}$ Heart Failure Unit, Cardiology, Hospital Clínic Barcelona, Barcelona, Spain, ${ }^{2}$ Section of Cardiovascular Medicine, \\ Department of Internal Medicine, Yale University School of Medicine, New Haven, CT, United States, ${ }^{3}$ Heart Failure Unit, \\ Cardiology, University Clinical Hospital of Santiago de Compostela, Santiago de Compostela, Spain, ${ }^{4}$ Centro de \\ Investigación Biomédica en Red Enfermedades CardioVasculares (CIBERCV), Madrid, Spain, ${ }^{5}$ Cardiology Group, Health \\ Research Institute of Santiago de Compostela, Santiago de Compostela, Spain, ${ }^{6}$ Heart Failure Unit, Cardiology, Hospital \\ Universitario Central de Asturias, Oviedo, Spain, ${ }^{7}$ Health Research Institute of Principado de Asturias, Instituto de \\ Investigación Sanitaria del Principado de Asturias (IISPA), Oviedo, Spain
}

OPEN ACCESS

Edited by:

Giuseppe Vergaro,

Gabriele Monasterio Tuscany

Foundation (CNR), Italy

Reviewed by:

Yasuhiro lkeda,

Yamaguchi Prefectural Grand Medical

Center, Japan

Guido Pastorini,

Regina Montis Regalis Hospital, Italy

${ }^{*}$ Correspondence:

Beatriz Díaz Molina

beadimo@gmail.com

Specialty section:

This article was submitted to Heart Failure and Transplantation, a section of the journal

Frontiers in Cardiovascular Medicine

Received: 16 November 2020 Accepted: 26 March 2021

Published: 07 May 2021

Citation:

Farrero M, Bellumkonda L, Gómez Otero I and Díaz Molina B (2021) Sex and Heart Failure Treatment Prescription and Adherence. Front. Cardiovasc. Med. 8:630141.

doi: 10.3389/fcvm.2021.630141
Heart disease is the leading cause of death in both men and women in developed countries. Heart failure (HF) contributes to significant morbidity and mortality and continues to remain on the rise. While advances in pharmacological therapies have improved its prognosis, there remain a number of unanswered questions regarding the impact of these therapies in women. Current HF guidelines recommend up-titration of neurohormonal blockade, to the same target doses in both men and women but several factors may impair achieving this goal in women: more adverse drug reactions, reduced adherence and even lack of evidence on the optimal drug dose. Systematic under-representation of women in cardiovascular drug trials hinders the identification of sex differences in the efficacy and safety of cardiovascular medications. Women are also under-represented in device therapy trials and are 30\% less likely to receive a device in clinical practice. Despite presenting with fewer ventricular arrythmias and having an increased risk of implant complications, women show better response to resynchronization therapy, with lower mortality and HF hospitalizations. Fewer women receive advanced HF therapies. They have a better post-heart transplant survival compared to men, but an increased immunological risk needs to be acknowledged. Technological advances in mechanical circulatory support, with smaller and more hemocompatible devices, will likely increase their implantation in women. This review outlines current evidence regarding sex-related differences in prescription, adherence, adverse events, and prognostic impact of the main management strategies for HF.

Keywords: heart failure, sex, treatment, treatment-drug, adherence-compliance-persistence, ventricular assist device, heart transplantation

\section{INTRODUCTION}

Men and women have the same risk of developing heart failure (HF) throughout life. However, it is well-known that women develop the disease later in life. In addition, women have a higher prevalence of HF with preserved ejection fraction (HFpEF), the prevalence of which increases with age. This may partly explain the under-representation of women in pharmacologic and device therapy trials designed to treat HF with reduced EF (HFrEF) (1).

Sex based differences in pharmacokinetics and pharmacodynamics of pharmacological agents may explain the variable effects in men and women. However, given the smaller number of 
women included in clinical trials of HFrEF, where they represent less than one-third of the study population, we do not have accurate information. Unfortunately, the results of large clinical trials are often not analyzed separately by sex and we only have subgroup analyses so they cannot be fully extrapolated to women (2). The same under-representation applies to clinical trials for devices. Heart transplantation shows good outcomes in women, with lower long-term, cardiovascular and malignancy risk. Nevertheless, sex needs to be taken into account in order to select a suitable donor, tailor post-transplant immunosuppression and surveillance and address specific quality of live concerns and address reproductive health.

\section{SEX DIFFERENCES IN PHARMACODYNAMICS AND PHARMACOKINETICS}

There are important sex-dependent differences in pharmacokinetics (PK) and pharmacodynamics (PD) that need to be acknowledged to understand how specific cardiovascular drugs can affect women and men differently. The differences can affect absorption, metabolism, distribution, and elimination.

\section{Absorption}

For orally administered drugs, two main factors need to be acknowledged: compared to men, women (1) produce less gastric fluid, which can lead to a decrease in the absorption of weak acids and an increase in the absorption of weak bases and (2) have longer intestinal transit time $(3,4)$. The influence of estrogen on enzymes such as CYP3A can modulate intestinal transport, elimination rate, and alcohol distribution volume (3). Transdermal absorption appears to be higher in women (3).

\section{Distribution}

Total body water is greater in men, while women have a higher proportion of adipose tissue. Therefore, distribution volume for hydrophilic or lipophilic drugs varies according to sex.

Plasmatic proteins involved in drug transport can be modulated by estrogens, resulting in a sex-dependent distribution $(5,6)$.

\section{Metabolism}

Lower hepatic flow in women, sex-dependent activity of metabolic enzymes, increased proportion of adipose tissue and lower basal metabolic rate can explain differences in drug metabolism $(3,7,8)$.

\section{Elimination}

In general, glomerular filtration, tubular secretion, and tubular reabsorption are higher in men (3), however, during pregnancy, renal blood flow increases and an overall increase in glomerular filtration rate by about $50 \%$ is seen in pregnant women (9).

Liver enzyme activity decreases in presence of elevated female hormone levels which may decrease drug elimination. Therefore, metabolism can change throughout the menstrual cycle, during pregnancy, with oral contraceptives intake or after menopause (10).

\section{SEX BASED DIFFERENCES IN PHARMACOKINETICS AND PHARMACODYNAMICS OF CARDIOVASCULAR DRUGS}

\section{Digoxin}

An increased risk of death in women was reported in the DIG trial. Although it may have been related to higher digoxin levels in women, it could not be proven since digoxin levels were available in less than one third of the study patients (11).

\section{Betablockers}

Women have higher plasma levels of beta-blocker (BB) due to decreased renal clearance $(\mathrm{Cl})$ and smaller distribution volume (Vd) (12). Despite this, BB have been shown to have greater therapeutic effect in men: In a chronic angina study with metoprolol, women had significantly higher heart rate and blood pressure both a rest and during exercise (13), despite similar effects on the reduction in the frequency of anginal episodes.

\section{Inhibitors of the}

\section{Renin-Angiotensin-Aldosterone System}

Sex-based differences have not been identified on the antihypertensive effects of angiotensin-converting enzyme inhibitors (ACEI), angiotensin-receptor blockers (ARB) and aliskiren (3). Although higher ARB maximum serum concentration $\left(\mathrm{C}_{\max }\right)$ and area under the curve (AUC) were found in women, the differences disappeared when adjusted for weigh (14).

\section{Sacubitril/Valsartan}

The potential effects of age and sex on the PK of Sacubitril/Valsartan were assessed in a study that enrolled 36 subjects, $50 \%$ male and 50\% female: No sex-dependent differences were found in PK (15).

\section{Diuretics}

$\mathrm{C}_{\max }$ and AUC of torsemide are $30-40 \%$ higher in women due to reduced elimination (16).

\section{Nitrates}

$\mathrm{C}_{\max }$ and $\mathrm{AUC}$ of isosorbide-5-mononitrate are higher in women, likely requiring weight adjustment and titration based on symptoms (17).

\section{Calcium-Channel Blockers}

Sex-specific PK differences have been described for verapamil, nifedipine, and amlodipine. Oral clearance of verapamil and amlodipine is faster in women compared to men, due to the higher activity of CYP3A4 and lower activity of P-gp (18).

\section{Thrombolytics, Antithrombotics, and Anticoagulants}

Warfarin dosage is strongly associated with sex, with lower requirements in women. Exogenous estrogen and testosterone can influence warfarin protein binding, so dose adjustment may be needed if hormone replacement therapy is initiated (12). 


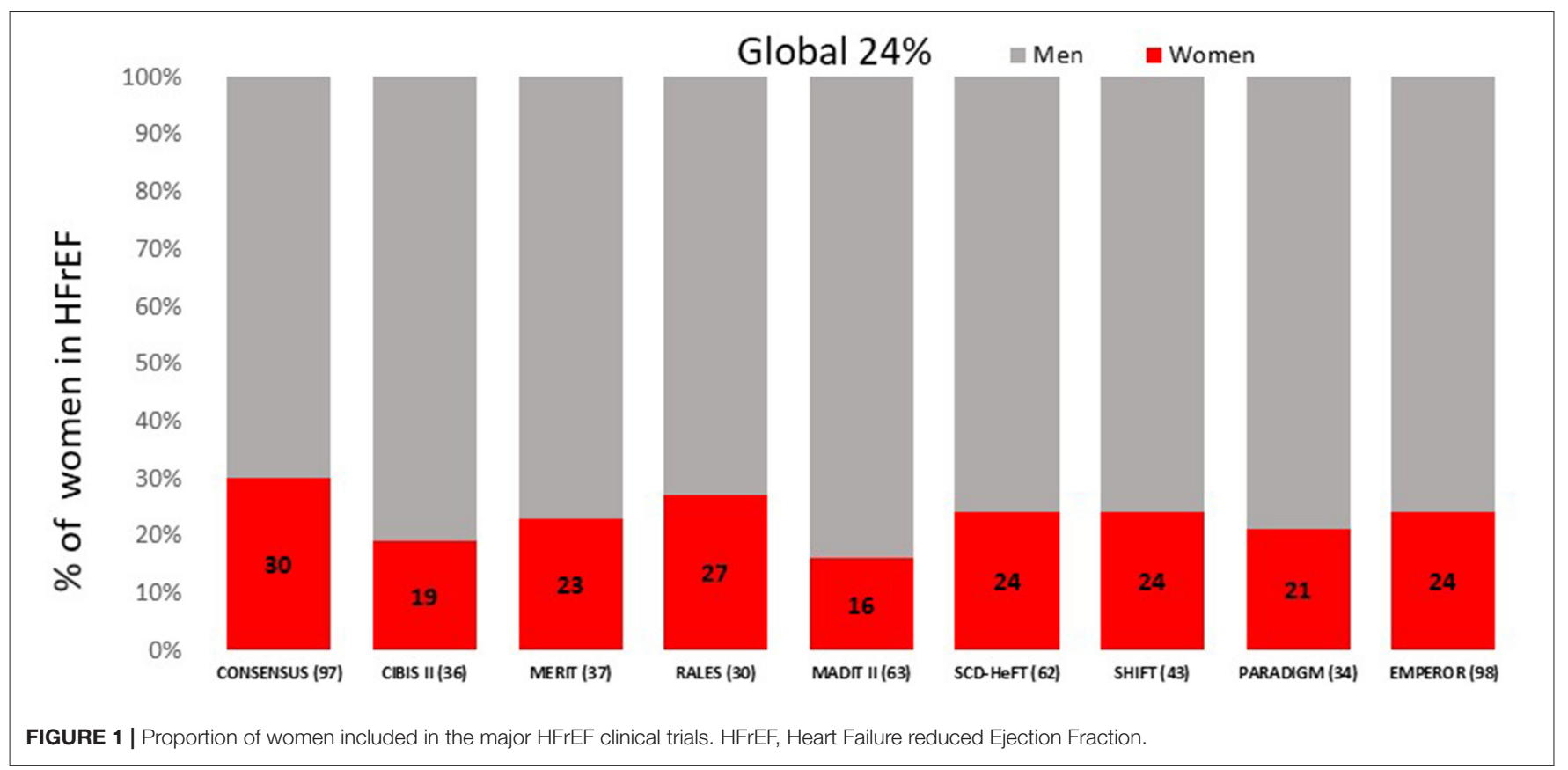

There is limited data regarding sex differences in direct oral anticoagulants (DOACs). But safety and efficacy studies suggest the importance of dose adjustment based on body weight. In a DOAC meta-analysis including 66,389 patients $(37.8 \%$ women), DOACs were associated with a significantly lower risk of major bleeding in women compared to men (RR 0.86; $95 \%$ CI 0.78-0.94) and a higher risk of stroke and systemic embolism compared with men (RR 1.19; 95\% CI 1.04-1.35) (19).

\section{SEX REPRESENTATION IN HEART FAILURE CLINICAL TRIALS}

More than 30 years ago, the National Institutes of Health (NIH) established guidelines for the inclusion of women and minorities in clinical research. They recommend that clinical trials should enroll equal numbers of men and women in order to understand sex differences. Shortly thereafter, Congress approved these recommendations, and they became law. The Food and Drug Administration (FDA) published another regulation requiring detailed information by sex in clinical trials investigating new drugs, and therapies (20).

Clinical trials however, unfortunately, remain underpowered to identify statistically significant treatment effects in both sexes.

A recent study assessed the enrollment of women in 36 cardiovascular trials evaluating different drugs approved by FDA from 2005 to 2015. Adequacy between the percentage of women included in the trials and the prevalence of the female sex in the disease studied, was evaluated using the participation to prevalence ratio (PPR). A relationship between 0.8 and 1.2 was considered to reflect a good representation of women population. It should be noted that in the $3 \mathrm{HF}$ trials included in this study women inclusion ranged from 22 to $40 \%$. The overall PPR was

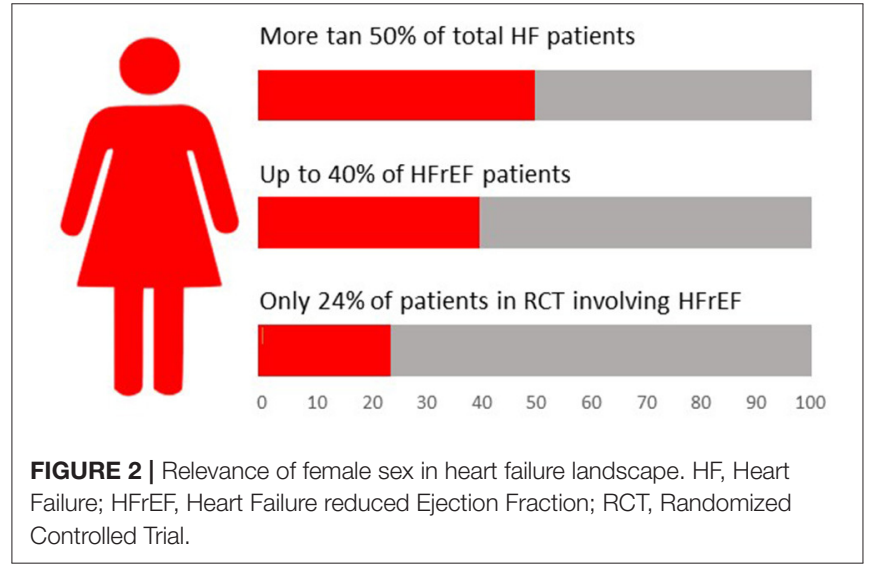

0.5 , reflecting an inclusion of women in the trials well below their prevalence of the disease. More recent trials show the same pattern, ranging from 21 to $29 \%$ inclusion of women (21) (Figure 1).

In heart failure (HF) clinical trials, women represent approximately a quarter of patients with HFrEF and over half of those with HFpEF. However, epidemiologic data demonstrate a much higher proportion of women suffering the disease in the real world $(22,23)$ (Figure 2).

The differences between real world proportion of women with heart failure and their representation in clinical trials may depend on a variety of factors: more comorbidities, older age in women, fulfilling exclusion criteria more frequently, lower proportion of HFrEF, less investigator counseling or less personal availability, and willingness to enroll. 


\section{Sex Differences in Pharmacological Treatment of Heart Failure Angiotensin-Converting Enzyme Inhibitors (ACEI)}

The first clinical trials with ACEI date back to the late 1980s. A sub-analysis of the SOLVD trial (24) revealed a significant reduction in the combined outcome of CHF-related death and hospitalization in men (39.5 vs. $29.7 \%$ in the placebo and enalapril arm, respectively), but not in women (38.7 vs. $37.0 \%$ ). Similar findings were reported other early trials with ACEI (CONSENSUS-1, SAVE) (25). A later meta-analysis including 30 randomized clinical trials on ACEI, evaluating data from more than 5,000 men and 1,500 women, showed a significant reduction in overall mortality and HF hospitalization in men, but not in women (26). The small proportion of women included in the trials may explain the lack of positive results (27).

\section{Angiotensin II Receptor Blockers (ARB)}

When large trials of ARB in HFrEF populations (ELITE, ValHeFT, CHARM) explored sex-specific treatment effect they found no differences in mortality or HF hospitalization between women and men (16). ELITE II compared losartan with captopril in HFrEF patients and no difference based on sex was noted (28).

However, a population study comparing ACEI with ARB in HF, including 10,223 women (8,627 ACEI and 1,596 ARB) and 9,475 men (8,484 ACEI and $991 \mathrm{ARB})$, showed that women on ARBs had a better survival than those on ACE inhibitors, with a $31 \%$ relative risk reduction in all-cause mortality (adjusted HR $0.69,95 \%$ CI $0.59-0.80, p<0.0001)$. Conversely, there was no survival difference between ACEI or ARB in men (HR 1.10, 95\% CI 0.95-1.30) (29).

Hormone effects on angiotensin II receptor expression or differences in adverse events may explain the potential superiority of ARB in women.

\section{Mineralocorticoid Receptor Antagonists (MRA)}

The studies assessing the role of mineralocorticoid receptor antagonist (MRA) in HFrEF (spironolactone in RALES and eplerenone in EPHESUS), showed no sex differences in prognosis $(30,31)$. In subgroup analysis of the EPHESUS study, female sex was associated with a reduction in all-cause mortality, while no differences were seen in men. Nevertheless, the interaction between the sex and the treatment arm was not significant.

In the TOPCAT trial, there were no sex-specific differences in the primary outcome (32). Nevertheless, in a secondary analysis of TOPCAT, restricted to 1,767 patients ( $49.9 \%$ women) enrolled in the Americas, spironolactone showed a reduction on mortality, with a trend toward greater reduction in cardiovascular mortality in women compared to men ( 9.0 vs. $13.2 \%$, respectively, $p=$ 0.051) (33).

\section{Sacubitril-Valsartan}

The PARADIGM-HF trial, showed superiority of sacubitril/valsartan compared to enalapril at reducing mortality and HF hospitalization in patients with HFrEF (34). In subgroup analyses, similar prognostic benefit was found for the primary endpoint in both men and women. When cardiovascular death was analyzed separately, sacubitril/valsartan showed a significant improvement in prognosis in men, but not in women (34), probably due to the small number of women included.

The PARAGON-HF trial, comparing sacubitril-valsartan and valsartan in patients with HFpEF, found no differences in primary composite end point of first and recurrent hospitalization for $\mathrm{HF}$ and death from $\mathrm{CV}$ causes. The primary composite endpoint occurred less frequently in women 0.73 (95\% CI $0.59-0.90$ ) compared to men $1.03(0.84-1.25 ; p=0.017)(35)$, primarily due to the reduction in HF hospitalization. Men were found to have a greater improvement in KCCQ-CSS than women. There were no sex differences in NYHA class, renal function, and adverse events.

In conclusion, PARAGONF_HF subanalysis suggest that sacubitril-valsartan may lead to greater reduction in HF hospitalizations in women with HFpEF.

\section{Betablockers (BB)}

Despite the low proportion of women included in BB trials (3638) and lack of a specific design to study sex-differences, post-hoc pooled analysis confirmed similar and significant benefits of $\mathrm{BB}$ (bisoprolol, carvedilol, metoprolol) on combined end-point of all-cause mortality and all-cause hospitalizations in both women and men (39).

Interestingly, data from the earlier US-Carvedilol-Study (40), CIBIS II trial (41) and SENIORS study (42), suggest a greater survival benefit from BBs treatment in women, but no mechanistic explanation is described.

\section{Ivabradine}

The SHIFT trial, comparing ivabradine and placebo in patients with symptomatic chronic HFrEF (LVEF $\leq 35 \%$ ) in sinus rhythm with heart rate $>70 \mathrm{bpm}$, showed a reduction in the composite primary outcome of $\mathrm{CV}$ death or hospital admission for worsening HF. Subgroup analyses did not show any sexdifferences in efficacy or safety of ivabradine (43).

\section{Sodium-Glucose Cotransporter-2 Inhibitors (SGLT2i)}

In the last 6 years, several large cardiovascular outcome trials evaluated the effect of iSGLT2 in patients with type 2 diabetes and established cardiovascular disease or those with high cardiovascular risk, they have consistently shown to reduce the risk of hospitalization for heart failure (44-49).

A meta-analysis of SGLT2i including patients with type 2 diabetes enrolled in the EMPA-REG OUTCOME, CANVAS Program, DECLARE TIMI-58, and CREDENCE trials, showed (50) no sex differences in safety or efficacy outcomes (all $p$ interaction $\geq 0.17$ ).

Recently, a meta-analysis condensing two single large-scale trials (DAPA-HF trial and EMPEROR-reduced trial) in patients with HFrEF with or without diabetes assessing the effects of SGLT2i on cardiovascular outcomes have been published. SGLT2i reduced hospitalizations for HF and death, with an improvement in renal outcomes, regardless of sex and other 
conditions such as age, diabetes status, or baseline heart failure medications (51).

\section{Other Heart Failure Medications Diuretics}

The effects of diuretics on mortality and morbidity in chronic heart failure have not been studied in large clinical trials. There are no reported sex-related differences with diuretic therapy. Observational studies have shown a relationship between diuretics dose and mortality risk, which was maintained after adjusting for sex (52).

\section{Digoxin}

In the DIG trial, digoxin was associated with a significantly higher risk of death among women (adjusted HR 1.23; 95\% confidence interval, 1.02-1.47), with no increased risk in men (11). Subsequent retrospective analyses showed a strong relationship between serum digoxin concentrations and survival (53). Comprehensive analysis of data indicates a beneficial effect of digoxin on morbidity (HR $0.73,95 \%$ CI $0.58-0.93, p=0.011$ ) and no excess mortality in women at serum concentrations between 0.5 and $0.9 \mathrm{ng} / \mathrm{ml}$, whereas serum concentrations $\geq 1.2 \mathrm{ng} / \mathrm{ml}$ was harmful (HR 1.33, 95\% CI 1.001-1.76, $p=0.049$ ).

Overall, whereas higher digoxin levels tend to increase mortality in women, low concentrations seem to be safe and associated with improved symptoms.

\section{Hydralazine-Isosorbide Dinitrate}

The A-HEFT trial enrolled more than 5,000 black women (41\% of total cohort) with moderate to severe heart failure (NYHA class III-IV) (54) to test treatment with hydralazine-isosorbide nitrate vs. placebo.

Treatment with hydralazine and isosorbide showed a significant reduction in mortality, first heart failure hospitalization, and change in quality of life at 6 months, with no differences between men and women.

\section{SAFETY: HEART FAILURE DRUGS AND ADVERSE REACTIONS IN WOMEN}

Women are known to have an increased adverse reaction (AR) to cardiovascular drugs compared to men (1.5-1.7fold) (3) and have greater hospital admissions. Despite this fact, there is little emphasis on sex-specific differences in AR in drug trials. In a recent systematic review (55), only 7\% of heart failure drug studies reported sex-based AR data. Differences in adverse events may be due to differences in absorption, body composition, drug distribution, physiological hormone changes and excretion (Table 1). These effects may be more pronounced in women with $\mathrm{HF}$ as they are older and have a higher prevalence of comorbidities and polypharmacy (60).
TABLE 1 | Heart failure drugs pharmacodynamics, efficacy and adverse events in women compared to men.

\begin{tabular}{|c|c|c|}
\hline Drug & Summary & References \\
\hline Digoxin & $\begin{array}{l}\text { - } \uparrow \text { Death risk with less benefit in } \\
\text { hospitalization. Related to higher } \\
\text { dosage in women, considering their } \\
\text { lower body weight. }\end{array}$ & $(11,53)$ \\
\hline Beta-blockers & $\begin{array}{l}\text { - } \uparrow \text { Plasma levels with the same } \\
\text { doses due to lower distribution } \\
\text { volume (hydrophilic drugs) and } \\
\text { slower clearance. } \\
\text { - Similar or higher benefit in women. }\end{array}$ & $\begin{array}{c}(12,35-39,41, \\
42)\end{array}$ \\
\hline ACE-inhibitors & $\begin{array}{l}\text { - Less benefit in women in clinical } \\
\text { trials, but underrepresented (bias?). } \\
\text { - } \uparrow \text { Angioedema and cough. } \\
\text { - Teratogenic. }\end{array}$ & $(25-27,56)$ \\
\hline ARB & $\begin{array}{l}\text { - Little evidence of more benefit in } \\
\text { women. }\end{array}$ & $(16,28,29,57)$ \\
\hline Sacubitril/valsartan & $\begin{array}{l}\text { - Similar } \\
\text { pharmacokinetic parameters. } \\
\text { - Similar results in HFrEF } \\
\text { hospitalizations but less reduction } \\
\text { in CV death } \\
\text { (underrepresented, bias?). } \\
\text { - Less HF hospitalizations in HFpEF. }\end{array}$ & $(15,34,35)$ \\
\hline $\begin{array}{l}\text { Mineralocorticoid } \\
\text { receptor antagonists }\end{array}$ & $\begin{array}{l}\text { - Similar or more benefit in women. } \\
\text { - Lower withdrawal. }\end{array}$ & $(30-33,58)$ \\
\hline Diuretics & $\begin{array}{l}\text { - } \uparrow \text { Serum concentration due to } \\
\text { reduced elimination. } \\
\text { - More electrolyte imbalance. }\end{array}$ & $(16,52,59)$ \\
\hline Nitrates & $\begin{array}{l}\text { - } \uparrow \text { Serum concentration: need to } \\
\text { adjust for weight. }\end{array}$ & $(17)$ \\
\hline Ivabradine & - No sex differences on effectiveness. & $(43)$ \\
\hline iSGLT2 & $\begin{array}{l}\text { - Similar effectiveness and adverse } \\
\text { events. }\end{array}$ & $(44-51)$ \\
\hline
\end{tabular}

ACE, angiotensin converting enzyme; ARB, angiotensin receptor blockers; HF, heart failure; HFrEF, heart failure with reduced ejection fraction; HFpEF heart failure with preserved ejection fraction; CV death, cardiovascular death; iSGLT2, sodium-glucose co-transportrer-2 (SGLT2) inhibitors; $\uparrow$, Increased.

\section{Diuretics}

Women experience greater electrolyte imbalance with diuretic use, which in turn increases the arrhythmic risk. For instance, women have an increased risk of drug-induced torsades de pointes (2.3-fold) related to a longer corrected QT interval induced by the effects of estradiol on potassium and calcium channel modulation (59).

\section{Digoxin}

A post hoc analyses of the DIG study (11) showed a $20 \%$ higher death risk in women (HR 1.2, CI 1.02-1.47), with no impact on mortality in men. Moreover, digoxin showed less benefit in reducing hospitalization in women, compared to men. This may be related to dosage, since differences disappeared when dose was adjusted for ideal body weight.

\section{Beta-Blockers}

Women present higher plasma levels of beta-blocker due to a lower distribution volume (higher percentage of fat in women, 
beta-blockers are hydrophilic drugs) and a slower clearance. Dosage needs to be adjusted according to these differences to prevent AR.

\section{Angiotensin-Converting Enzyme Inhibitors}

An increased risk of angioedema and cough (2-fold) has been described in women (56). Moreover, their potential teratogenic effects need to be acknowledged in women during childbearing years.

\section{Angiotensin II Receptor Blockers}

No significant sex-differences in risk of kidney impairment, hypotension, or hyperkalemia have been described with the use of Losartan (57).

\section{Mineralocorticoid Receptor Antagonists}

There seems to be a higher withdrawal rate in men due to the appearance of gynecomastia (seen in $5.3 \%$ of the men) (58).

\section{ADVANCED HEART FAILURE THERAPIES IN WOMEN: DEVICES AND HEART TRANSPLANTATION}

\section{Implantable Cardioverter Defibrillator}

Implantable Cardioverter Defibrillators (ICD) have shown to reduce sudden death risk in heart failure patients with reduced ejection fraction, especially of ischemic etiology. Therefore, they have a class $1 \mathrm{~A}$ indication according to current guidelines for primary prevention in patients with left ventricular ejection fraction (LVEF) $<35 \%$ despite optimal medical therapy (61).

These recommendations are based on classical studies, such as SCD-HeFT (62), MADIT II (63), or DANISH (64), where female representation was small $(23,15$, and $27 \%$, respectively). In fact, women with heart failure (HF) are less likely to receive an ICD or counseling for ICD. In a large observational study (65) including 21,059 patients from 236 sites, $19.3 \%$ women vs. $24.6 \%$ men $(p<0.001)$ were offered ICD implantation. Of note, the same proportion of men and women underwent the implant once it was advised ( 63.1 vs. $62.3 \%, p=n s$ ). In another observational study 32.2 per 1,000 men and 8.6 per 1,000 women received ICD therapy. After controlling for demographic variables and comorbidity, men were 2.44 (95\% CI 2.30-2.59) times more likely to receive an ICD compared to women.

The reduced rate of ICD implantations in women may be related in part to the controversies regarding efficacy and higher risk of complications in women compared to men.

Although some device studies show a similar survival benefit after ICD implantation in both men and women, most are underpowered to study sex differences. In a metanalyses including 4,744 primary prevention ICD patients (66) $(19.6 \%$ female), there was a $22 \%$ reduction in mortality in men but no benefit in women. In fact, ventricular arrythmias may be less common amongst women. The risk of sudden death was $32 \%$ lower in women compared to men in 8,337 HF patients cohort with no ICD (67). Women have consistently shown to have fewer appropriate ICD shocks. In a metanalyses (68) including 7,229 patients $(22 \%$ female), women had a HR for appropriate ICD shocks of 0.63 (95\% CI $0.49-0.82, p \leq 0.001)$ compared to men and no significant benefit on mortality. In a European study (69) analyzing data from 14 registries in 11 countries (5,033 patients, $19 \%$ female), an appropriate ICD shock occurred in $8 \%$ of women vs. $14 \%$ of men, $p=0.0002$. In the Ontario ICD Database (70) (6,021 patients, $22 \%$ female), women showed a HR 0.69 (95\% CI 0.51-0.93) for ICD shock and HR 0.73 (95\% CI 0.59-0.90) for appropriate antitachycardia pacing compared to men. Etiology of cardiomyopathy and scar burden may account in part for these differences. In addition, sex hormones and their influence on myocardial ion channels $(\mathrm{Ca}, \mathrm{K})$ could play a role as well (71).

ICD related complications have been reported more frequently in women. In the Ontario ICD Database (70) women were 1.9 times more likely to have a major complication within the first year after implant, including lead dislodgement. In the National Cardiovascular Data Registry (72) (38,912 initial single or dual-chamber ICD implants, $25 \%$ female) women showed higher odds of procedural complications within 90 days OR 1.30 (95\% CI 1.26-1.53, $p<0.001$ ). The reasons for the differences in the complication rate are unclear but could be related to delayed presentation or greater severity of illness. Smaller vessel size and a thinner walled right ventricle may explain a higher rate of pneumothorax or perforation. Increased bleeding risk have also been reported in women.

Overall, studies show sex differences in arrhythmic risk and ICD-related complications. Nevertheless, there is a risk of sudden death in women with HF and reduced LVEF that could be prevented by ICD implantation. Careful and individualized assessment is required to identify patients that would benefit the most from this therapy.

\section{Cardiac Resynchronization Therapy}

Cardiac Resynchronization Therapy (CRT) has shown to improve functional capacity and survival amongst patients with $\mathrm{LVEF}<35 \%$, left bundle block $>130-150 \mathrm{~ms}$ and NYHA functional class II-IV and therefore has a class $1 \mathrm{~A}$ indication in current HF guidelines (73). Several studies have reported underutilization of CRT in women (74). A recent study (75) using registry data of 311,009 patients undergoing CRT implantation between 2006 and 2012 showed that only 30\% were women, and women were less likely to have an ICD associated to the CRT. Interestingly however, women had a higher CRT response score compared to men. These disparities increased over the study period. In a Swedish registry (76), female sex was again associated with lower CRT implantation. Despite this, most of the studies suggest similar if not better response to CRT in women.

The CARE-HF (77) ( $n=752,28 \%$ female) and COMPANION (78) ( $n=1,520,32 \%$ female) trials demonstrated similar reduction in mortality and time to hospitalization in both sexes after CRT implant. In the MASCOT (79) trial $(n=393,21 \%$ female) women showed better left ventricular remodeling and lower mortality and HF hospitalizations after adjustment for cardiovascular risk factors. Remarkably, women showed wider QRS and smaller left ventricle size at enrollment. In another study that only included patients with non-ischemic cardiomyopathy ( $n=212,49.5 \%$ female) CRT response among women was greater ( 84 vs. $58 \%, p<0.001$ ) than in men, despite similar 
baseline QRS duration (80). In fact, women showed better response compared to men at all QRS widths below $180 \mathrm{~ms}$. In a retrospective analysis (81) of 619 consecutive patients (19\% women) undergoing CRT implantation in a single center over a 10 -year period, female sex was the only independent predictor of all-cause mortality (HR 0.44, 95\% CI 0.21-0.90, $p=0.025$ ) and showed a trend toward lower heart failure hospitalization. In a metanalyses (82) of 5 randomized control trials $(n=3,496$, $23 \%$ female), QRS duration was the only independent predictor of CRT benefit. Further analysis showed the benefit was even more significant at lower height. There was a higher proportion of women amongst the wider QRS and shorter patients.

As we discussed for ICD, complication rate seems to be higher in women after CRT implant. In the MADIT-CRT trial, women were twice as likely as men to experience a major procedurerelated adverse event ( 6.3 vs. $2.7 \% ; p<0.001)$ mainly related to pneumothorax, infection or bleeding. The main risk factor for complications seemed to be size and body mass index both in women and men.

Overall, women show a better response to CRT after adjusting for non-ischemic etiology of the cardiac disease. Reasons are not clearly established but this benefit could be related to a smaller ventricle size with easier conduction between the leads and presence of more typical left bundle branch block.

\section{Ventricular Assist Device}

Mechanical circulatory support has expanded significantly in the recent years, with over 13,000 implants in the INTERMACS registry (83) between 2014 and 2018, of which only 22\% were women. Technical evolution has enabled devices to become smaller and to evolve from pulsatile flow first to axial-flow and now to centrifugal flow with full magnetic levitation. This has led to a significant decrease in morbidity and mortality and increase in implantations. Left ventricular assist devices (LVAD) are now smaller and more hemocompatible. Despite this, in the MOMENTUM3 (84) trial, HeartMate3's pivotal trial, only $21 \%$ of the participants were women.

There are no sex differences in survival either in pulsatile or continuous flow devices according to INTERMACS registry (85). Complications are frequent, and include driveline infection, bleeding, pump thromboses, right ventricular failure, and neurological events. There is scarcity of data on the incidence of these complications according to sex, although several reports suggest that there might be a higher incidence of neurological events in women. In an INTERMACS registry study $(n=1,936$, $21 \%$ female) female sex was associated with an increased risk of first neurological event (HR 1.44, 95\% CI 1.05-1.96; $p=$ 0.020 ), with no difference in other complications. In a later paper focusing on stroke rates during support with continuous-flow LVAD, female sex was also a predictor of stroke (HR 1.51, 95\% CI 1.25-1.82; $p<0.001)$. The same was reported in an analysis of more than 900 HeartMate II outpatients (86) (23\% female), where female sex was a risk factor for both hemorrhagic and ischemic stroke. There is lack of data on the impact of sex in stroke rate with HeartMate3 since the event rate in MOMENTUM3 was too low to derive conclusions.
There is no clear explanation as to why fewer women receive LVAD compared to men. Some aspects to consider are smaller body surface area, smaller ventricles, older age at the time of HF diagnosis and a higher prevalence of HF with preserved ejection (87), which is not suitable for LVAD support. Since there might be a risk for selection bias, we need to be aware that women benefit as much as men from this life-saving therapy, with no significant increase in complications specially with the newer generation LVAD devices.

\section{Heart Transplantation}

Heart Transplantation (HT) is the therapy of choice to improve survival in patients with end-stage HF. Mean survival after HT nowadays is 12.5 years for the adult population and 12-21 years for the pediatric population (88). Rejection and infection are the most concerning complications in the first year post-HT, whereas the leading cause of death after the first year are coronary allograft vasculopathy and malignancy.

Women are again under-represented in the field of HT: according to the last report from the International Society for Heart and Lung Transplantation (88), only a quarter of the HT were performed in women $(25 \%$ in Europe, $26 \%$ in the United States of America, and $24 \%$ in other countries). There is also a smaller proportion of women amongst the donors (37\% in Europe, 30\% in the United States, and 22\% in other countries). Female HT receptors have shown a better life expectancy compared to male recipients: 12.2 vs. 11.4 years $(p<$ 0.001) (89).

Women are younger than men at the time of listing (mean 48 year for women vs. 56 years for men), have less ischemic heart disease and more idiopathic dilated cardiomyopathy, and fewer cardiovascular risk factors such as smoking, diabetes mellitus, hypertension, or tobacco use (89). On the other hand, women are less likely to be transplanted in the higher emergency status, as they are also less frequently supported with temporary mechanical circulatory devices.

In the post HT period, women are at a lower risk of coronary allograft vasculopathy and malignancy. These differences could explain longer survival in female HT recipients.

Pre-HT sensitization and post-HT rejection risk are higher in women, related predominantly to the presence of circulating preformed HLA antibodies due to sensitization from previous pregnancies (90). Donor-recipient matching is key at the time of HT. Sex mismatch has been reported as a prognostic factor for HT outcomes, with best outcomes reported with female donor to female recipient and the worst with female donor to male recipient. A simple explanation for this fact, is the undersizing of female donor hearts when used for male recipients, however, outcome differences seem to persist even after adjustment for ventricular mass (91).

In summary, fewer women receive HT, despite their better long-term survival. Sex specificities need to be considered in the pre-HT evaluation (greater sensitization, fewer cardiovascular risk factors), at the time of transplant (sex and size donorrecipient matching) and in the long-term post-HT follow-up 
TABLE 2 | Advanced heart failure therapies in women: summary and key messages.

\begin{tabular}{|c|c|c|}
\hline Intervention & Summary & References \\
\hline $\begin{array}{l}\text { Implantable } \\
\text { cardioverter device }\end{array}$ & $\begin{array}{l}\text { - Women under represented in ICD } \\
\text { trials (15-27\%). } \\
\text { - Less likely to receive counseling for ICD. } \\
\text { - Fewer ventricular arrythmias and } \\
\text { appropriate ICD shocks. } \\
\text { - Higher rates of } \\
\text { complications (pneumo/hemothorax). }\end{array}$ & $(62-72)$ \\
\hline $\begin{array}{l}\text { Cardiac } \\
\text { resynchronization } \\
\text { therapy }\end{array}$ & $\begin{array}{l}\text { - CRT under utilized in women (30\%). } \\
\text { - Women show better response to CRT } \\
\text { (left ventricular remodeling, mortality and } \\
\text { HF hospitalizations). } \\
\text { - Wider QRS complex with classic left } \\
\text { bundle branch block and smaller } \\
\text { ventricles may explain better CRT } \\
\text { response in women. } \\
\text { - Higher rates of complications } \\
\text { during implantation. }\end{array}$ & (73-82) \\
\hline $\begin{array}{l}\text { Mechanical } \\
\text { circulatory support }\end{array}$ & $\begin{array}{l}\text { - Fewer women (22\%) receive MCS. } \\
\text { - Similar overall outcomes as men in both } \\
\text { pulsatile and continuous flow devices. } \\
\text { - Greater risk of neurological events in } \\
\text { women (ischemic and hemorrhagic). } \\
\text { - New generation smaller and more } \\
\text { hemocompatible devices could increase } \\
\text { implant rates in women. }\end{array}$ & $(83-87)$ \\
\hline $\begin{array}{l}\text { Heart } \\
\text { transplantation }\end{array}$ & $\begin{array}{l}\text { - Fewer HT are performed in } \\
\text { women (25\%). } \\
\text { - Women have better post transplant } \\
\text { survival, related to pre HT factors } \\
\text { (younger age, less cardiovascular risk } \\
\text { factors) and post HT factors (less } \\
\text { allograft vasculopathy } \\
\text { and malignancies). } \\
\text { - Women have increased immunological } \\
\text { risk (sensitization and rejection) }\end{array}$ & $(88-90)$ \\
\hline
\end{tabular}

ICD, implantable cardioverter device; CRT, cardiac resynchronization therapy; MCS, mechanical circulatory support; HT, heart transplantation.

(increased risk of rejection but lower risk of graft vasculopathy and malignancies) (Table 2).

\section{SEX DIFFERENCES IN ADHERENCE}

Adherence to long-term therapies for chronic diseases in developed countries averages only about $50-75 \%$ (2). Inadequate adherence is associated with increased long-term mortality in patients with heart failure (92).

Few studies have aimed to assess the effect of sex on adherence to HF drugs. Granger et al. analyzed adherence among participants in the CHARM trial $(n=7,599)$ and they found that $11 \%$ were poor adherers $(<80 \%, n=836)$. Poor adherers were more likely to be women $(12.7 \%$ of women vs. $10.2 \%$ of men; $p=0.002$ ), have a higher heart rate, and a greater number of concomitant illnesses (93).

Kayiband et al. performed an inception cohort study of new users of evidence-based HF drug treatment. They included 28,067
Canadian patients (13,453 women, 14,614 men) between January 2000 and December 2008 who had a follow-up > 1 year after HF drug treatment initiation. In this study women were more likely than men to be adherent to their treatment (52.8 and $50.1 \%$, respectively, adjusted proportion ratios: 0.96 , 95\% CI: $0.94-$ 0.99) (94). More recently, a retrospective, observational study was carried out in the Dutch population. Twenty-five thousand seven hundred and seventy-six patients with a diagnosis code for chronic HF between January 2012 and December 2014 were included in order to study the impact of sex differences in comorbidities and medication adherence on a composite endpoint of all-cause mortality or HF admission. 11,259 (45\%) women and 14,517 men, median age 76 and 72 years, respectively, were analyzed after a median follow-up of 3.3 years, and only slight differences in HF drugs adherence between women and men were found with no impact on the composite endpoint (95).

We can conclude that non-adherence to disease-modifying drugs is associated with an increased mortality and HF readmissions, but adherence seems to be similar between sexes (Figure 3).

\section{DISCUSION}

Although women represent $50 \%$ of the world population and despite similar overall prevalence of heart failure among men and women (96) women are significantly underrepresented in clinical trials for heart failure. The trend has not changed significantly over time, with similarly low inclusion rate for women in the newer HFrEF trials. For example, women represented $30 \%$ of the study population in the enalapril CONSENSUS trial (97), in 1987, and $19 \%$ in the bisoprolol CIBIS II trial in 1999 (36) and represented $24 \%$ of the study population in the EMPEROR trial (98), published in 2020. This may be due to a higher proportion of women with HFpEF, older age and more comorbidities, limiting their chances of being included in HFrEF trials. In HFpEF trials, such as PARAGON (99) or TOPCAT (32), women represent $50 \%$ of the study population, which is higher compared to HFrEF trials, but still low in comparison to the percentage of women in the population with HFpEF. In fact, $H F$ is the discipline of cardiology in which women are most underrepresented (21) in clinical trials.

Women are generally more symptomatic than men when they present with HFrEF (100), which could in turn be related to a later medical contact, minimization of symptoms, acceptance of a poorer quality of life (101) and a prioritization of their social role as caregivers. Due to underrepresentation in clinical trials, we have limited information on the efficacy and adverse effects of therapies in women. In a recent study on the use of guideline recommended therapy for $\mathrm{HF}$ and its titration, women had a similar proportion of HF drug and dose prescription compared to men, at baseline and at 1-year follow up. Considering the differences in adherence, absorption, metabolism, body weight and adverse events between men and women, it would be reasonable to establish a more tailored therapy according to sex. The main limitation for an individualized approach 


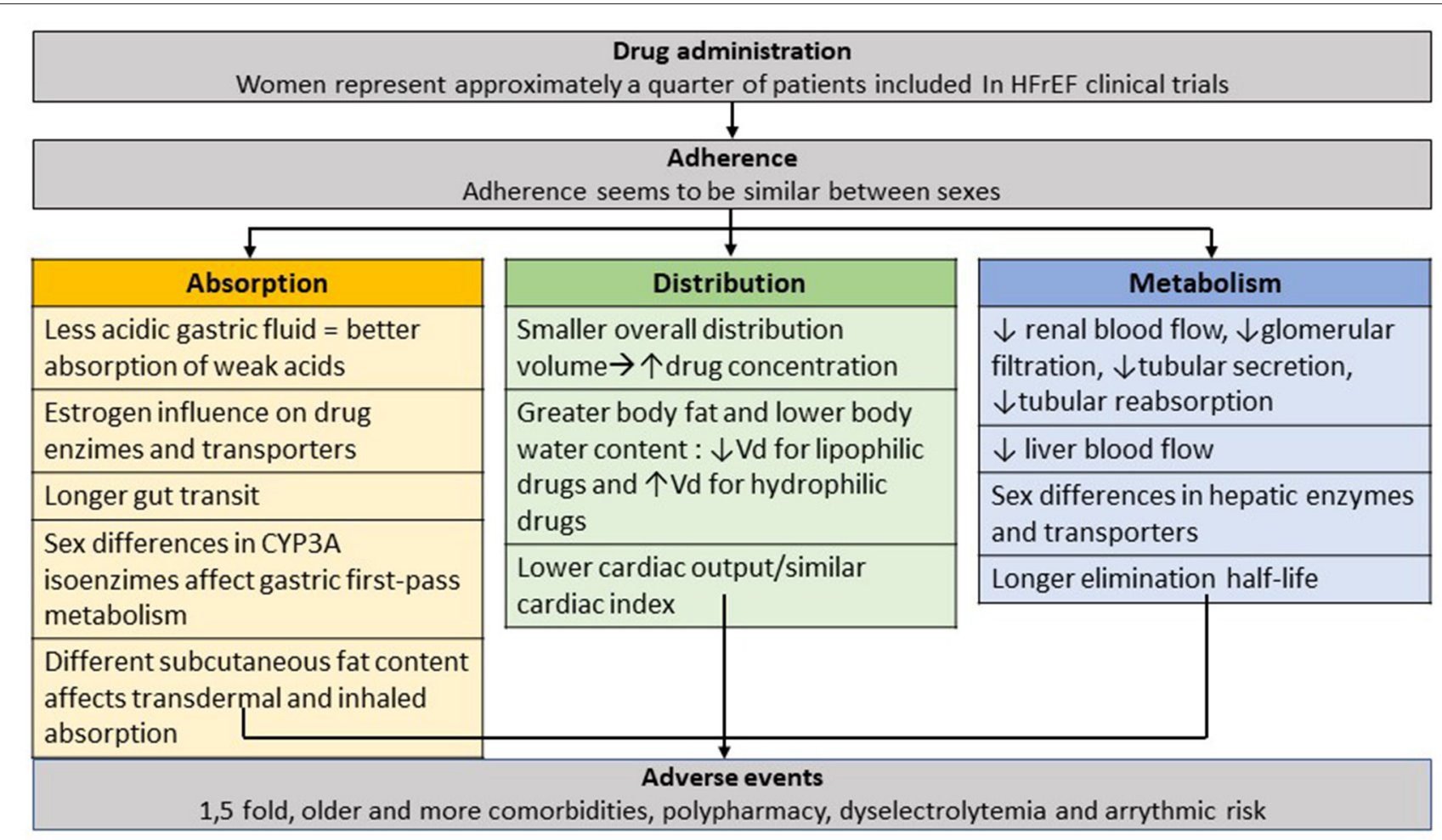

FIGURE 3 | Use of heart failure drugs in women. Sex-differences on prescription, adherence, effective circulation levels and adverse events. HFrEF, Heart Failure reduced Ejection Fraction.

remains to be the lack of reliable data. Santema et al. (102) showed how, despite achievement of similar target doses of HF guideline recommended therapy in men and women, the lowest hazards of death for men occurred at $100 \%$ of the recommended dose, whereas women showed 30\% lower risk at $50 \%$ of the recommended dose, with no further decrease in risk at higher doses.

Women are also less likely to receive lifesaving therapies such as LVAD (103) and HT. LVAD therapy has shown similar survival benefits in women compared to men, but women tend to be more unstable at the time of implant, with worse INTERMACS profiles and more severe tricuspid regurgitation (104). In the HT arena, despite similar overall survival, women are more likely to receive hearts from higher risk donors (105).

Reproductive health counseling, teratogenic effect of $\mathrm{HF}$ medications and pregnancy management for women with $\mathrm{HF}$ are some important topics that affect women uniquely and that need

\section{REFERENCES}

1. Walsh MN, Jessup M, Lindenfeld J. Women with heart failure: unheard, untreated, and unstudied. $J \mathrm{Am}$ Coll Cardiol. (2019) 73:41-3. doi: 10.1016/j.jacc.2018. 10.041 to be a focus for future research and discussion, especially for those in need of advanced HF therapies and devices.

\section{CONCLUSIONS AND FUTURE PERSPECTIVES}

Despite high prevalence of HF in women, there is lack of data on the use of drugs and HF therapies, with limited enrolment in randomized control trials and limited access to lifesaving strategies. Future trials should focus on greater enrollment of women in heart failure therapeutics and devote resources to understand the pathophysiology of the sex differences and disparities in access to advanced therapies.

\section{AUTHOR CONTRIBUTIONS}

All authors listed have made a substantial, direct and intellectual contribution to the work, and approved it for publication. 
4. Caballeria J, Baraona E, Rodamilans M, Lieber CS. Effects of cimetidine on gastric alcohol dehydrogenase activity and blood ethanol levels. Gastroenterology. (1989) 96:388-92. doi: 10.1016/0016-5085(89)91562-X

5. Smith SA, Waters NJ. Pharmacokinetic and pharmacodynamic considerations for drug binding to alpha-1-acid glycoprotein. Pharm Res. (2019) 36:30. doi: 10.1007/s11095-018-2551-x

6. Kuhl H. Pharmacology of estrogens and progestogens: influence of different routes of administration. Climateric. (2005) 8(Suppl. 1):363. doi: 10.1080/13697130500148875

7. Shulman RW, Ozdemir V. Psychotropic medications and cytochrome P450 2D6: pharmacokinetic considerations in the elderly. Can J Psychiatry. (1997) 42(Suppl. 1):4-9.

8. Gandhi M, Aweeka F, Greenblatt R, Blaschke TF. Sex differences in pharmacokinetics and pharmacodynamics. Annu Rev Pharmacol Toxicol. (2004) 44:499-523. doi: 10.1146/annurev.pharmtox.44.101802.121453

9. Davison JM, Dunlop W. Renal hemodynamics and tubular function normal human pregnancy. Kidney Int. (1980) 18:152-61. doi: 10.1038/ki.1980.124

10. Draper CF, Duisters K, Weger B, Chakrabarti A, Harms AC, Brennan L, et al. Menstrual cycle rhythmicity: metabolic patterns in healthy women. Sci Rep. (2018) 8:14568. doi: 10.1038/s41598-018-32647-0

11. Rathore SS, Wang Y, Krumholz HM. Sex-based differences in the effect of digoxin for the treatment of heart failure. N Engl J Med. (2002) 347:140311. doi: 10.1056/NEJMoa021266

12. Rosano G, Lewis B, Agewall S, Wassmann S, Vitale C, Schmidt H, et al. Gender differences in the effect of cardiovascular drugs: a position document of the Working Group on Pharmacology and Drug Therapy of the ESC. Euro Heart J. (2015) 36:2677-80. doi: 10.1093/eurheartj/ehv161

13. Cocco G, Chu D. The anti-ischemic effect of metoprolol in patients with chronic angina pectoris is gender-specific. Cardiology. (2006) 106:14753. doi: 10.1159/000092769

14. Kalibala J, Pechère-Bertsch A, Desmeules J. Gender differences in cardiovascular pharmacotherapy-the example of hypertension: a mini review. Front Pharmacol. (2020) 11:564. doi: 10.3389/fphar.2020.00564

15. Gan L, Langenickel T, Petruck J, Kode K, Rajman I, Chandra P, et al. Effects of age and sex on the pharmacokinetics of LCZ696, and angiotensin receptor neprilysin inhibitor. J Clin Pharmacol. (2016) 56:7886. doi: $10.1002 /$ jcph. 571

16. Tamargo J, Rosano G, Walther T, Duarte J, Niesser A, Kaski JC, et al. Gender differences in the effects of cardiovascular drugs. Euro Heart J Cardiovasc Pharmacother. (2017) 3:163-82. doi: 10.1093/ehjcvp/pvw042

17. Vree TB, Dammers E, Valducci R. Sex-related differences in the pharmacokinetics of isosorbide-5-mononitrate $(60 \mathrm{mg})$ after repeated oral administration of two different original prolonged release formulations. Int $J$ Clin Pharmacol Ther. (2004) 42:463-72. doi: 10.5414/CPP42463

18. Tamai I, Saheki A, Saitoh R, Sai Y, Yamada I, Tsuji A. Nonlinear intestinal absorption of 5-hydroxytryptamine receptor antagonist caused by absorptive and secretory transporters. J Pharmacol Exp Ther. (1997) 283:108-15.

19. Raccah BH, Perlman A, Zwas DR, Hochberg-Klein S, Masarwa R, Muszkat $\mathrm{M}$, et al. Gender differences in efficacy and safety of direct oral anticoagulants in atrial fibrillation: systematic review and network meta-analysis. Ann Pharmacother. (2018) 52:1135-42. doi: 10.1177/1060028018771264

20. Kim ESH, Menon V. Status of women in cardiovascular clinical trials. Arterioscler Thromb Vasc Biol. (2009) 29:27983. doi: 10.1161/ATVBAHA.108.179796

21. Scott PE, Unger EF, Jenkins MR, Southworth MR, McDowell TY, Geller RJ, et al. Participation of women in clinical trials supporting FDA approval of cardiovascular drugs. J Am Coll Cardiol. (2018) 71:19609. doi: 10.1016/j.jacc.2018.02.070

22. Tsao CW, Lyass A, Enserro D, Larson MG, Ho JE, Kizer JR, et al. Temporal trends in the incidence of and mortality associated with heart failure with preserved and reduced ejection fraction. J Am Coll Cardiol HF. (2018) 6:678-85. doi: 10.1016/j.jchf.2018.03.006

23. Shah KS, Xu H, Matsouaka RA, Bhatt DL, Heidenreich P, Hernandez $\mathrm{AF}$, et al. Heart failure with preserved, borderline, and reduced ejection fraction: 5-year outcomes. J Am Coll Cardiol. (2017) 70:2476-86. doi: 10.1016/j.jacc.2017.08.074

24. Limacher MC, Yusef S, SOLVD Investigator. Gender differences in presentation, morbidity and mortality in the Studies of Left Ventricular
Dysfunction (SOLVD); a preliminary report. In: Wenger NK, Speroff L, Packard B, editors. Cardiovascular Health and Disease in Women. Greenwich, CT: Le Jacq Communications (1993). p. 345-8.

25. Regitz-Zagrosek V. Therapeutic implications of the gender-specific aspects of cardiovascular disease. Nat Rev Drug Discov. (2006) 5:425-38. doi: 10.1038/nrd2032

26. Garg R, Yusuf S. Overview of randomized trials of angiotensin-converting enzyme inhibitors on mortality and morbidity in patients with heart failure. Collaborative Group on ACE Inhibitor Trials. JAMA. (1995) 273:14506. doi: 10.1001/jama.273.18.1450

27. Shekelle PG, Rich MW, Morton SC, Atkinson CS, Tu W, Maglione M, et al. Efficacy of angiotensin converting enzyme inhibitors and beta-blockers in the management of left ventricular systolic dysfunction according to race, gender, and diabetic status: a meta-analysis of major clinical trials. J Am Coll Cardiol. (2003) 41:1529-38. doi: 10.1016/S0735-1097(03)00262-6

28. Pitt B, Poole-Wilson PA, Segal R, Martínez FA, Dickstein K, Camm AJ, et al. Effect of losartan compared with captopril on mortality in patients with symptomatic heart failure: randomised trial-the Losartan Heart Failure Survival Study ELITE II. Lancet. (2000) 355:1582-7. doi: 10.1016/S0140-6736(00)02213-3

29. Hudson M, Rahme E, Behlouli H, Sheppard R, Pilote L. Sex differences in the effectiveness of angiotensin receptor blockers and angiotensin converting enzyme inhibitors in patients with congestive heart failure - a population study. Eur J Heart Fail. (2007) 9:602-9. doi: 10.1016/j.ejheart.2007.02.001

30. Pitt B, Zannad F, Remme WJ, Cody R, Castaigne A, Perez A, et al. The effect of spironolactone on morbidity mortality in patients with severe heart failure. Randomized Aldactone Evaluation Study Investigators. N Engl J. Med. (1999) 341:709-17. doi: 10.1056/NEJM199909023411001

31. Pitt B, Remme W, Zannad F, Neaton J, Martínez F, Ronker B, et al. Eplerenone, a selective aldosterone blocker, in patients with left ventricular dysfunction after myocardial infarction. N Engl J Med. (2003) 348:130921. doi: 10.1056/NEJMoa030207

32. Pitt B, Pfeffer MA, Assmann SF, Boineau MD, Anand IS, Claggett B, et al. Spironolactone for heart failure with preserved ejection fraction. $N$ Engl J Med. (2014) 370:1383-92. doi: 10.1056/NEJMoa1313731

33. Merrill M, Sweitzer NK, Lindenfeld J, Kao DP. Sex differences in outcomes and responses to spironolactone in heart failure with preserved ejection fraction. J Am Coll Cardiol HF. (2019) 7:228-38. doi: 10.1016/j.jchf.2019.01.003

34. McMurray JJ, Packer M, Desai AS, Gong J, Lefkowitz MP, Rizkala $\mathrm{AD}$, et al. Angiotensin-neprilysin inhibition versus enalapril in heart failure. Engl J Med. (2014) 371:993-1004. doi: 10.1056/NEJMoa 1409077

35. McMurray JJV, Jackson AM, Lam CSP, Redfield M, Anand IS, $\mathrm{Be} J$, et al. Effects of Sacubitril-Valsartan versus valsartan in women compared with men with heart failure and preserved ejection fraction: insights from PARAGON-HF. Circulation. (2020) 141:338-51. doi: 10.1161/CIRCULATIONAHA.119.044491

36. CIBIS-II Investigators and Committees. The Cardiac Insufficiency Bisoprolol Study II (CIBIS-II): a randomised trial. Lancet. (1999) 353:9-13. doi: 10.1016/S0140-6736(98)11181-9

37. MERIT-HF Study Group. Effect of metoprolol CR/XL in chronic heart failure: metoprolol CR/XL randomised intervention trial in congestive heart failure (MERIT-HF). Lancet. (1999) 353:2001-7. doi: 10.1016/S0140-6736(99)04440-2

38. Packer M, Coats AJ, Fowler MB, Katus HA, Krum H, Mohacsi P, et al. Effect of carvedilol on survival in severe chronic heart failure. Engl J Med. (2001) 344:1651-8. doi: 10.1056/NEJM200105313442201

39. Ghali JK, Piña IL, Gottlieb SS, Deedwania PC, Wiskstrand JC. Metoprolol CR/XL in female patients with heart failure: analysis of the experience in metoprolol extended-release randomized intervention trial in heart failure (MERIT-HF). Circulation. (2002) 105:1585-91. doi: 10.1161/01.CIR.0000012546.20194.33

40. Packer M, Bristow MR, Cohn JN, Colucci WS, Fowler MB, Gilbert EM, et al. U.S. Carvedilol Heart Failure Study Group. The effect of carvedilol on morbidity and mortality in patients with chronic heart failure. N Engl J Med. (1996) 334:1349-55. doi: 10.1056/NEJM19960523334 2101 
41. Simon T, Mary-Krause M, Funck-Brentano C, Jaillon P. Sex differences in the prognosis of congestive heart failure: results from the Cardiac Insufficiency Bisoprolol Study (CIBIS II). Circulation. (2001) 103:37580. doi: 10.1161/01.CIR.103.3.375

42. Flather MD, Shibata MC, Coats AJ, van Veldhuisen DJ, Parkhomenko A, Borbola J, et al. SENIORS Investigators. Randomized trial to determine the effect of nebivolol on mortality and cardiovascular hospital admission in elderly patients with heart failure (SENIORS). Eur Heart J. (2005) 26:21525. doi: 10.1093/eurheartj/ehi115

43. Swedberg K, Komajda M, Böhm M, Borer JS, Ford I, DubostBrama A, et al. Ivabradine and outcomes in chronic heart failure (SHIFT): a randomised placebo-controlled study. Lancet. (2010) 376:875-85. doi: 10.1016/S0140-6736(10)61198-1

44. Zinman B, Wanner C, Lachin JM, Fitchett D, Bluhmki E, Hantel S, et al. Empagliflozin, cardiovascular outcomes, and mortality in type 2 diabetes. N Engl J Med. (2015) 373:2117-28. doi: 10.1056/NEJMoa 1504720

45. Neal B, Perkovic V, Mahaffey KW, de Zeeuw D, Flucher G, Erondu N, et al. Canagliflozin and cardiovascular and renal events in type 2 diabetes. $N$ Engl J Med. (2017) 377:644-57. doi: 10.1056/NEJMoa1611925

46. Wiviott SD, Raz I, Bonaca MP, Mosenzon O, Kato ET, Cahn A, et al. Dapagliflozin and cardiovascular outcomes in type 2 diabetes. $N$ Engl J Med. (2019) 380:347-57. doi: 10.1056/NEJMoa1812389

47. Perkovic V, Jardine MJ, Neal B, Bompoint S, Heerspink JJL, Chayrtan DM, et al. Canagliflozin and renal outcomes in type 2 diabetes and nephropathy. N Engl J Med. (2019) 380:2295-306. doi: 10.1056/NEJMoa1811744

48. Januzzi J, Ferreira JP, Böhm M, Kaul S, Wanner Ch, Brueckmann M, et al. Empagliflozin reduces the risk of a broad spectrum of heart failure outcomes regardless of heart failure status at baseline. Eur J Heart Fail. (2019) 21:386-88. doi: 10.1002/ejhf.1419

49. Kato ET, Silverman MG, Mosenzon O, Zelniker TA, Cahn A, Furtado RHM, et al. Effect of dapagliflozin on heart failure and mortality in type 2 diabetes mellitus. Circulation. (2019) 139:2528-36. doi: 10.1161/CIRCULATIONAHA.119.040130

50. Rådholm K, Zhou Z, Clemens K, Neal B, Woodward M. Effects of sodiumglucose co-transporter-2 inhibitors in type 2 diabetes in women versus men. Diabetes Obes Metab. (2020) 22:263-6. doi: 10.1111/dom.13876

51. Zannad F, Ferreira JP, Pocock SJ, Anker SD, Butler J, Filippatos G, et al. SGLT2 inhibitors in patients with heart failure with reduced ejection fraction: a meta-analysis of the EMPEROR-Reduced and DAPA-HF trials. Lancet. (2020) 396:819-29. doi: 10.1016/S0140-6736(20)31824-9

52. Eshaghian S, Horeich TB, Foranow GC. Relation of loop diuretic dose to mortality in advanced heart failure. Am J Cardiol. (2006) 97:175964. doi: 10.1016/j.amjcard.2005.12.072

53. Adams KF, Patterson JH, Gattis WA, O'Connor CM, Lee CR, Schwartz T, et al. Relationship of serum digoxin concentration to mortality and morbidity in women in the digitalis investigation group trial: a retrospective analysis. J Am Coll Cardiol. (2005) 46:497-504. doi: 10.1016/j.jacc.2005.02.091

54. Taylor AL, Lindenfeld J, Ziesche S, Walsh MN, Mitchell JE, Adams K, et al. Outcomes by gender in the African-American Heart Failure Trial. J Am Coll Cardiol. (2006) 48:2263-7. doi: 10.1016/j.jacc.2006.06.020

55. Bots SH, Groepenhoff F, Eikendal ALM, Tannenbaum C, Rochon PA, RegitzZagrosek V, et al. Adverse drug reactions to guideline-recommended heart failure drugs in women: a systematic review of the literature. JACC Heart Fail. (2019) 7:258-66. doi: 10.1016/j.jchf.2019.01.009

56. Do TP, Seetasith A, Belleli R, Schlienger RG, Corda S, Burudpakdee Ch, et al. A database cohort study to assess the risk of angioedema among patients with heart failure initiating angiotensin-converting enzyme inhibitors in the USA. Am J Cardiov Drugs. (2018) 18:205-11. doi: 10.1007/s40256-0170256-X

57. Kiernan MS, Wentworth D, Francis G, Martinez FA, Dickstein K, Komajda $\mathrm{M}$, et al. Predicting adverse events during angiotensin receptor blocker treatment in heart failure: results from the HEAAL trial. Eur J Heart Fail. (2012) 14:1401-9. doi: 10.1093/eurjhf/hfs145

58. Lopes RJ, Lourenço AP, Mascarenhas J, Azevedo A, Bettendourt P. Safety of spironolactone use in ambulatory heart failure patients. Clin Cardiol. (2008) 31:505-59. doi: 10.1002/clc.20284
59. Hreiche R, Morissette P, Turgeon J. Drug-induced log QT syndrome in women: review of current evidence and remaining gaps. Gend Med. (2008) 5:124-35. doi: 10.1016/j.genm.2008.05.005

60. Mastromarino V, Casenghi M, Testa M, Gabriele E, Coluccia R, Rubattu S, et al. Polypharmacy in heart failure patients. Curr Heart Failure Rep. (2014) 11:212-9. doi: 10.1007/s11897-014-0186-8

61. Al-Khatib SM, Stevenson WG, Ackerman MJ, Bryant WJ, Callans DJ, Curtis $\mathrm{AB}$, et al. 2017 AHA/ACC/HRS guideline for management of patients with ventricular arrhythmias and the prevention of sudden cardiac death. A report of the American College of Cardiology/American Heart Association Task Force on clinical practice guidelines and the Heart Rhythm Society. Heart Rhythm. (2018) 15:e73-189. doi: 10.1016/j.hrthm.2017.10.036

62. Bardy GH, Lee KL, Mark DB, Poole JE, Packer DL, Boineau R, et al. Amiodarone or an implantable cardioverter-defibrillator for congestive heart failure. N Engl J Med. (2005) 352:225-37. doi: 10.1056/NEJMoa043399

63. Moss AJ, Zareba W, Hall J, Klein H, Wilber D, Cannom DS, et al. Prophylactic implantation of a defibrillator in patients with myocardial infarction and reduced ejection fraction. N Engl J Med. (2002) 346:87783. doi: 10.1056/NEJMoa013474

64. Kober L, Thune JJ, Nielsen JC, Haarbo J, Videbaek L, Korup E, et al. Defibrillator implantation in patients with nonischemic systolic heart failure. N Engl J Med. (2016) 375:1221-30. doi: 10.1056/NEJMoa1608029

65. Hess PL, Hernandez AF, Bhatt DL, Hellkamp AS, Yancy CW, Schwamm LH, et al. Sex and race/ethnicity differences in implantable cardioverter-defibrillator counseling and use among patients hospitalized with heart failure. Circulation. (2016) 134:517-26. doi: 10.1161/CIRCULATIONAHA.115.021048

66. Ghanbari H, Dalloul G, Hasan R, Daccarett M, Saba S David S, et al. Effectiveness of implantable cardioverter-defibrillators for the primary prevention of sudden cardiac death in women with advanced heart failure. Arch Intern Med. (2009) 169:1500-6. doi: 10.1001/archinternmed.2009.255

67. Rho RW, Patton KK, Poole JE, Cleland JG, Shadman R, Anand $\mathrm{I}$, et al. Important differences in mode of death between men and women with heart failure who would qualify for a primary prevention implantable cardioverter-defibrillator. Circulation. (2012) 126:2402-7. doi: 10.1161/CIRCULATIONAHA.111.069245

68. Santangeli P, Pelargonio G, Dello Russo A, Casella M, Bisceglia C, Bartoletti $S$, et al. Gender differences in clinical outcome and primary prevention defibrillator benefit in patients with severe left ventricular dysfunction: a systematic review and meta-analysis. Heart Rhythm. (2010) 7:87682. doi: 10.1016/j.hrthm.2010.03.042

69. Sticherling C, Arendacka B, Svendsen JH, Wijers S, Friede T, Stockinger J, et al. Sex differences in outcomes of primary prevention implantable cardioverter-defibrillator therapy: combined registry data from eleven European countries. Europace. (2018) 20:963-70. doi: 10.1093/europace/eux176

70. MacFadden D, Crystal E, Krahn AD, Mangat I, Healey JS, Dorian P, et al. Sex differences in implantable cardioverter-defibrillator outcomes: findings from a prospective defibrillator database. Ann Int Med. (2012) 156:195203. doi: 10.7326/0003-4819-156-3-201202070-00007

71. Gillis AM. Atrial fibrillation and ventricular arrhythmias. Sex differences in electrophysiology, epidemiology, clinical presentation, and clinical outcomes. Circulation. (2017) 135:593608. doi: 10.1161/CIRCULATIONAHA.116.025312

72. Russo AM, Daugherty SL, Masoudi FA, Wang Y, Curtis J, Lampert R. Gender ant outcomes after primary prevention implantable cardioverterdefibrillator implantation: findings from the National Cardiovascular Data Registry (NCDR). Am Heart J. (2015) 170:330-8. doi: 10.1016/j.ahj.2015. 02.025

73. Ponikowski P, Voors AA, Anker S, Bueno H, Cleland JGF, Coats AJS, et al. 2016 ESC guidelines for the diagnosis and treatment of acute and chronic heart failure: The Task Force for the diagnosis and treatment of acute and chronic heart failure of the European Society of Cardiology (ESC). Eur Heart J. (2016) 37:2129-200. doi: 10.1093/eurheartj/ehw128

74. Sridhar ARM, Yarlagadda V, Parasa S, Reddy YM, Patel D, Lakkireddy $\mathrm{D}$, et al. Cardiac resynchronization therapy. US trends and disparities in utilization and outcomes. Circ Arrhythm Electrophysiol. (2016) 9:e003108. doi: 10.1161/CIRCEP.115.003108 
75. Chatterjee N, Borgquist R, Chang Y, Lewey J, Jackson VA, Singh J, et al. Increasing sex differences in the use of cardiac resynchronization therapy with or without implantable cardioverter-defibrillator. Eur Heart J. (2017) 38:1485-94. doi: 10.1093/eurheartj/ehw598

76. Lund LH, Braunschweig F, Benson L, Stahlberg M, Dahlström U, Linde C. Association between demographic, organizational, clinical, and socioeconomic characteristics and underutilization of cardiac resynchronization therapy: results from the Swedish Heart Failure Registry. Eur J Heart Fail. (2017) 19:1270-9. doi: 10.1002/ejhf.781

77. Cleland JGF, Daubert JC, Erdmann E, Freemantle N, Gras D, Kappenberger $\mathrm{L}$, et al. The effect of cardiac resynchronization on morbidity and mortality in heart failure. N Engl J Med. (2005) 352:1539-49. doi: 10.1056/NEJMoa050496

78. Bristow MR, Saxon LA, Boehmer J, Krueger S, Kass DA, De Marco T, et al. Cardiac-resynchronization therapy with or without an implantable defibrillator in advanced chronic heart failure. N Engl J M. (2004) 350:214050. doi: 10.1056/NEJMoa032423

79. Schuchert A, Muto C, Maounis T, Frank R, Ella RO, Polauck A, et al. Genderrelated safety and efficacy of cardiac resynchronization therapy. Clin Cardiol. (2013) 36:683-90. doi: 10.1002/clc.22203

80. Varma N, Manne M, Nguyen D, He J, Niebauer M, Tchou P. Probability and magnitude of response to cardiac resynchronization therapy according to QRS duration and gender in nonischemic cardiomyopathy and LBBB. Heart Rhythm. (2014) 11:1139-47. doi: 10.1016/j.hrthm.2014.04.001

81. Zabarovskaja S, Gadler F, Braunschweig F, Stahlberg M, Hörnsten J, Linde C. Women have better long-term prognosis than men after cardiac resynchronization therapy. EP Europace. (2012) 14:1148-55. doi: 10.1093/europace/eus039

82. Linde C, Cleland JGF, Gold MR, Daubert JC, Tang ASL, Young JB. The interaction of sex, height, and QRS duration on the effects of cardiac resynchronization therapy on morbidity and mortality: an individual-patient data metaanalysis. Eur J Heart Fail. (2018) 20:780-91. doi: 10.1002/ejhf.1133

83. Teuteberg JJ, Cleveland JC, Cowger J, Higgins RS, Goldstein DJ, Keebler M. The society of thoracic surgeons intermacs 2019. Annual report: changing landscape of devices and indications. Ann Thorac Surg. (2020) 109:64960. doi: 10.1016/j.athoracsur.2019.12.005

84. Mehra MR, Uriel N, Yoshifumi N, Cleveland J, Yuzefpolskaya M, Salerno CT. A fully magnetically levitated left ventricular assist device-final report. $N$ Engl J Med. (2019) 380:1618-27. doi: 10.1056/NEJMoa1900486

85. Hsich EM, Naftel DC, Myers SL, Gorodeski EZ, Grady KL, Schmuhl Dl. Should women receive left ventricular assist device support? Findings form INTERMACS. Cir Heart Fail. (2012) 5:234-40. doi: 10.1161/CIRCHEARTFAILURE.111.963272

86. Boyle AJ, Jorde UP, Sun B, Park SJ, Milano CA, Frazier OH, et al. Pre-operative risk factors of bleeding and stroke during left ventricular assist device support. J Am Coll Cardiol. (2014) 63:880-8. doi: 10.1016/j.jacc.2013.08.1656

87. Hisch EM, Grau-Sepulveda MV, Hernandez AF, Eapen ZJ, Xian Y, Schwamm LH, et al. Relationship between sex, ejection fraction, and Btype natriuretic peptide levels in patients hospitalized with heart failure and associations with inhospital outcomes: findings from the Get With The Guideline-Heart Failure Registry. Am Heart J. (2013) 166:106371. doi: 10.1016/j.ahj.2013.08.029

88. Khush K, Cherikh WS, Chambers DC, Harhay MO, Hayes D, Hsich E, et al. The International Thoracic Organ Transplant Registry of the International Society for Heart and Lung Transplantation: Thirty-sixth adult heart transplantation report-2019; focus theme: donor and recipient size match. J Heart Lung Transpl. (2019) 38:1056-66. doi: 10.1016/j.healun.2019.08.004

89. Morris AA, Cole RT, Laskar SR, Kalogeropoulus A, Vega JD, Smith A, et al. Improved outcomes for women on the heart transplant wait list in the modern era. J Card Fail. (2015) 21:555-60. doi: 10.1016/j.cardfail.2015.03.009

90. Triulzi DJ, Kleinman S, Kakaiya RM, Busch MP, Norris Ph, Steele WR, et al. The effect of previous pregnancy and transfusion on HLA alloimmunization in blood donors: implications for a transfusion-related acute lung injury risk reduction strategy. Trasnfusion. (2009) 49:182535. doi: 10.1111/j.1537-2995.2009.02206.x

91. Reed RM, Netzer G, Hunsicker L, Mitchell BD, Rajagopal K, Scharf $S$, et al. Cardiac size and sex-matching in heart transplantation: size matters in matters of sex and the heart. JACC Heart Fail. (2014) 2:7383. doi: 10.1016/j.jchf.2013.09.005

92. Ruppar TM, Cooper PS, Mehr DR, Delgado JM, Dunbar-Jacob JM. Medication adherence interventions improve heart failure mortality and readmission rates: systematic review and meta-analysis for controlled trials. J Am Heart Assoc. (2016) 5:e002606. doi: 10.1161/JAHA.115. 002606

93. Granger BB, Ekman I, Granger CB, Ostergren J, Olofsson B, Michelson E, et al. Adherence to medication according to sex and age in the CHARM programme. Eur J Heart Fail. (2009) 11:1092-8. doi: 10.1093/eurjhf/ hfp 142

94. Kayibanda JF, Girouard C, Grégoire JP, Demers E, Moisan J. Adherence to the evidence-based heart failure drug treatment: are there sex-specific differences among new users? Res Social Adm Pharm. (2018) 14:91520. doi: 10.1016/j.sapharm.2017.10.010

95. Gürgöze M, van de Galiën OP, Limpens MAM, Roest S, Hoekstra RC, IJpma AS, et al. Impact of sex differences in co-morbidities and medication adherence on outcome in 25776 heart failure patients. ESC Heart Fail. (2021) 8:63-73. doi: 10.1002/ehf2.13113

96. Mehta PA, Cowie MR. Gender and heart failure: a population perspective. Heart. (2006) 92(Suppl. III):iii14-8. doi: 10.1136/hrt.2005.070342

97. CONSENSUS Trial Study Group. Effects of enalapril on mortality in severe congestive heart failure. Results of the Cooperative North Scandinavian Enalapril Survival Study (CONSENSUS). N Engl J Med. (1987) 316:142935. doi: 10.1056/NEJM198706043162301

98. Packer M, Anker SD, Butler J, Filippatos G, Pocock SJ, Carson P, et al. EMPEROR-reduced trial investigators. cardiovascular and renal outcomes with empagliflozin in heart failure. N Engl J Med. (2020) 383:1413-24. doi: 10.1056/NEJMoa2022190

99. Solomon S, McMurray J, Anand I, Phil D, Ge J, Lam CSP, et al. Angiotensin-Neprilysin inhibition in heart failure with preserved ejection fraction. N Engl J Med. (2019) 381:1609-20. doi: 10.1056/NEJMoa 1908655

100. Bozkurt B, Khalaf S. Heart failure in women. Methodist Debakey Cardiovasc J. (2017) 13:216-7. doi: 10.14797/mdcj-13-4-216

101. Lee $\mathrm{KH}, \mathrm{Xu} \mathrm{H}, \mathrm{Wu}$ B. Gender differences in quality of life among community-dwelling older adults in low- and middle-income countries: results from the Study on global AGEing and adult health (SAGE). BMC Public Health. (2020) 20:114. doi: 10.1186/s12889-020-8212-0

102. Santema BT, Ouwerkerk W, Tromp J, Sama IE, Ravera A, Regitz-Zagrosek $\mathrm{V}$, et al. Identifying optimal doses of heart failure medications in men compared with women: a prospective, observational, cohort study. Lancet. (2019) 394:1254-63. doi: 10.1016/S0140-6736(19)31792-1

103. Joshi AA, Lerman JB, Sajja A, Dahiya G, Gokhale AV, Dey A, et al. Sexbased differences in left ventricular assist device utilization. Insights from the nationwide inpatient sample 2004 to 2016. Circ Heart Fail. (2019) 12:e06082. doi: 10.1161/CIRCHEARTFAILURE.119.006082

104. Magnussen C, Bemhardt A, Ojeda FM, Wagner FM, Gummert J, de By TMMH, et al. Gender differences and outcomes in left ventricular assist device support: The European Registry for Patients with Mechanical Circulatory Support. J Heart Lung Transplant. (2017) 37:61-70. doi: 10.1016/j.healun.2017.06.016

105. Moayedi Y, Fan CPO, Cherikh W, Stehlik J, Teuteberg JJ, Ross HJ, et al. Survival outcomes after heart transplantation. Does recipient sex matter? Circ Heart Fail. (2019) 12:e006218. doi: 10.1161/CIRCHEARTFAILURE.119.006218

Conflict of Interest: The authors declare that the research was conducted in the absence of any commercial or financial relationships that could be construed as a potential conflict of interest.

Copyright (C) 2021 Farrero, Bellumkonda, Gómez Otero and Díaz Molina. This is an open-access article distributed under the terms of the Creative Commons Attribution License (CC BY). The use, distribution or reproduction in other forums is permitted, provided the original author(s) and the copyright owner(s) are credited and that the original publication in this journal is cited, in accordance with accepted academic practice. No use, distribution or reproduction is permitted which does not comply with these terms. 


\section{GLOSSARY}

AAG: alpha-1 acid glyconprotein

ACEI: angiotensin-converting enzyme (ACE) inhibitors AR: Adverse reaction

ARB: angiotensin-receptor blockers

AUC: area under the curve

BB: Betablockers

BMR: basal metabolic rates

BSA: body surface area

CI: Confidence Interval

CI: cardiac index

$\mathrm{Cl}$ : clearance

CO: cardiac output

CRT: Cardiac Resynchronization Therapy

CYP3A4: cytochrome P450 3A4

CV: cardiovascular
DOACs: direct oral anticoagulants

FDA: Food and Drug Administration

HF: heart failure

HFpEF: Heart Failure preserved Ejection Fraction

HFrEF: Heart Failure reduced Ejection Fraction

HR: Hazard Ratio

HT: Heart transplantation

ICD: Implantable Cardioverter Defibrillator

LVEF: left ventricular ejection Fraction

LVAD: Left Ventricular Assist Device

MRA: Mineralocorticoid receptor antagonists

NIH: National Institutes of Health

PK: pharmacokinetics

PD: pharmacodynamics

PPR: participation to prevalence ratio

SGLT2i: Sodium-glucose cotransporter-2 inhibitors

Vd: volume distribution 